ECCOMAS

Proceedia
COMPDYN 2021

$8^{\text {th }}$ ECCOMAS Thematic Conference on Computational Methods in Structural Dynamics and Earthquake Engineering M. Papadrakakis, M. Fragiadakis (eds.) Streamed from Athens, Greece, 28 - 30 June 2021

\title{
THE USE OF STICK-IT MODEL FOR EDP ASSESSMENT IN EXISTING RC INFILLED TYPOLOGIES
}

\author{
M. Gaetani d'Aragona ${ }^{1}$, M. Polese ${ }^{1}$, M. Di Ludovico ${ }^{1}$, and A. Prota ${ }^{1}$ \\ ${ }^{1}$ Department of Structures for Engineering and Architecture, University of Naples Federico II \\ Via Claudio 21, 80125, Naples, Italy \\ e-mail: \{marco.gaetanidaragona, maria.polese, marco.diludovico, andrea.prota\}@unina.it
}

\begin{abstract}
The estimation of expected seismic losses at regional scale represents a critical issue for the assessment of the seismic risk and for the evaluation of the seismic resilience of large communities. As a basic step, the assessment of economic losses requires the computation of the building performances in terms of engineering demand parameters such as interstorey drift ratios and peak floor accelerations in order to assess the distribution and the extent of the damage experienced by various building components. The Stick-IT model (Stick for Infilled frames Typologies) was recently proposed to predict the response, in terms of engineering demand parameters, for infilled RC building typologies. Stick-IT is a MDOF system consisting of a series of lumped masses connected by nonlinear shear link elements. The model parameters can be defined for building typologies starting from low level information that can be easily retrievable at the large scale via image-based processing techniques integrated with generic information about typical construction features, such as in plan dimensions, the number of stories or the percentage of infills openings and considering the infills consistency.

This paper adopts the Stick-IT model to predict damage and expected losses for a set of RC infilled buildings located in L'Aquila town. The application shows the advantages and the potentiality of the proposed model when adopted for large scale loss assessments.
\end{abstract}

Keywords: nonlinear response history analysis; IDR; PFA; Stick model.

ISSN:2623-3347 (C) 2021 The Authors. Published by Eccomas Proceedia. Peer-review under responsibility of the organizing committee of COMPDYN 2021. doi:10.7712/120121.8662.18854 


\section{INTRODUCTION}

The PEER framework [1] allows estimating the expected losses in the aftermath of damaging earthquakes involving a four-step procedure: hazard analysis, structural analysis, damage, and loss analysis. In this context, the structural analysis is required to calculate the building performances expressed in terms of engineering demand parameters (EDPs) such as interstory drift ratios (IDRs) and peak floor accelerations (PFAs). The EDPs may be used to predict the distribution and the extent of the damage in structural, non-structural components and building contents and then, relying on suitable cost functions, are often adopted to quantify the economic losses.

At the building level, the most complete procedure to assess building structural performances consists of performing Nonlinear Response History Analyses (NRHA) on refined finite element models (e.g., [2]). However, the structural modeling and computational effort required for the analysis at the single building level are not suitable also for large-scale analyses. To overcome this issue, faster and simpler approaches are required. In this sense, different approaches were proposed in the last years relying on static analysis performed on refined [3] or simplified models [4]-[6], or on NRHAs performed on simplified models (e.g., shear models [7]). The latter models has been demonstrated to describe the non-linear characteristics and failure modes of multi-story buildings with sufficient accuracy both at the building scale and at the regional scale, enabling to capture the story-level damage concentration due to seismic loads [8]-[10]. Further, appropriate calibration of the simplified MDOF model, depending on specific features of the building typologies to be assessed, improves the accuracy of response prediction [7]. Recently, in Gaetani d'Aragona et al. [11] a simplified multidegree of freedom (MDOF) model, named Stick-IT, was proposed to evaluate the response of building typologies representative of RC infilled moment resisting frames. The model was calibrated to represent the behavior of infilled Italian typologies and has been demonstrated to reliably predict the building response and direct economic losses when compared to more refined finite element models [12].

In Gaetani d'Aragona et al. [11] simplified formulas based on few geometrical and structural parameters are proposed to define the structural model. The formulations require assumptions in defining the infill consistency which may affect structural behavior and the assessment of repair costs [7]. The definition of these properties can be of difficult when dealing with the assessment of the behavior of a large building portfolio and need to be hypothesized on the basis of specific considerations based on construction techniques in force in the analyzed region also depending on the construction time. For this reason, in this paper, the impact of these assumptions on the assessment of repair costs is analyzed.

Following, the Stick-IT model is first briefly introduced. Next, the adopted methodology to evaluate expected seismic losses is described and an application of the model for L'Aquila town is presented.

\section{STICK-IT FOR RAPID EDP ASSESSMENT}

In Gaetani d'Aragona et al. [7], building typologies representative of RC infilled moment resisting frames are modeled with simplified Stick model (Stick-I), which is a MDOF NonLinear Shear Model consisting of a series of masses lumped at the story level and connected in series by means of nonlinear shear springs; the Stick-I model is developed for each direction of the building (see Figure 1). 


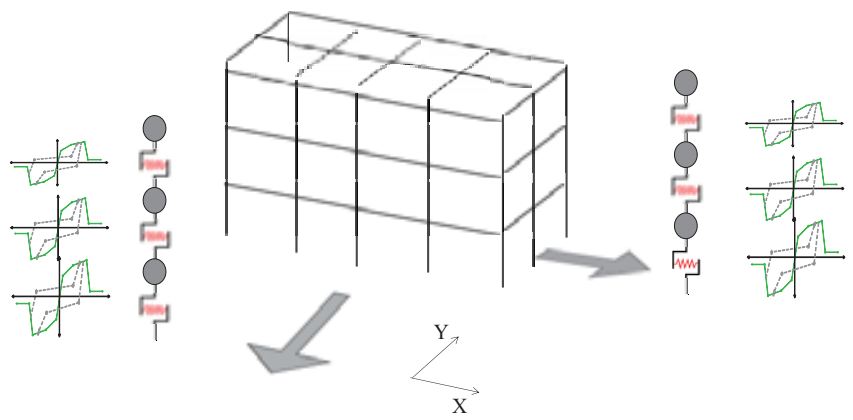

Figure 1: Simplified Stick model for infilled RC frames.

The story-level backbone of such spring is approximated by a four-linear backbone curve which can be defined based on 7 parameters (Figure 2). To simulate the hysteretic behavior, and in particular the pinched response and the strength and stiffness cyclic degradation of the story-level spring link element, the Pinching4 material available in OpenSees [13] is adopted. In general, such material requires the definition of 21 parameters governing the pinching response as well as stiffness and strength deterioration.

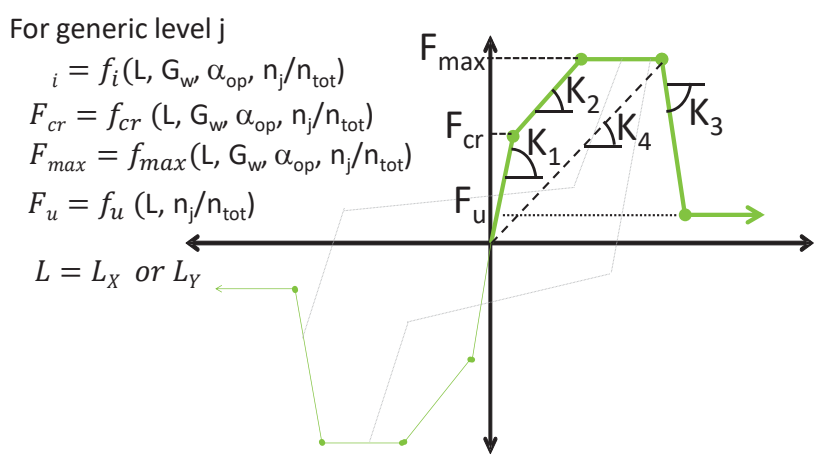

Figure 2: Definition of Stick-IT parameters for envelope curves.

In Gaetani d'Aragona et al. [11] an evolution of the stick model to predict the response of existing infilled RC typologies was introduced. The latter, denominated Stick-IT (i.e. StickI referred to a building Typology), is characterized by suitable parameters enabling to describe the backbone and hysteretic behavior at the generic story of the typology. In order to derive the story-level backbone and hysteretic parameters of Stick-IT, in [11] a regression study was performed on a large database, comprising 5632 Stick-I models. The database of Stick-I models was obtained with the following procedure: (a) assemble a large portfolio of building FE models with simulated design procedure; (b) determine the backbone (depending on 7 model parameters) for stick-I referring to longitudinal and transversal directions for all the building models in the generated portfolio; (c) perform calibration of the hysteretic behavior for stick-I model adopting a generic algorithm GA procedure and determine hysteretic model parameters ( 7 model parameters for the pinching4 material).

The regression study was finalized to describe the Stick-IT model as a function of few variables, mainly those ones that could be easily retrieved for large scale studies, e.g. from rapid on-site surveys or remote sensing procedures. As a result of the regression study performed in [11], given the building storey class $n_{s}$, the Stick-IT backbone curve at each story can be derived by the following parameters: dimension of the building in the analyzed direction ( $\mathrm{L}=\mathrm{L}_{\mathrm{x}}$ or $\mathrm{L}_{\mathrm{y}}$ depending if longitudinal or transversal direction is considered), the normal- 
ized storey number for the generic $i^{\text {th }}$ level $n_{n s i}\left(=i / n_{s}\right)$ and the opening percentage $\alpha_{o p}$, representing the area of openings for the infills with respect to of the infill area for each panel. In addition, the infill elastic shear modulus $\mathrm{G}_{\mathrm{w}}$ is considered to represent the infills consistency.

The model parameters for envelope curves are expressed with an exponential type formulation as in Eq. (1), that expresses the generic parameter $\mathrm{P}_{\mathrm{b}, \mathrm{i}}$ of the backbone curve at the ith storey:

$$
P_{b, i}=a_{1}+a_{2} \cdot L^{a_{3}} \cdot G_{w}^{a 4} \cdot\left(1-\alpha_{o p}\right)^{a 5} \cdot n_{n s i}^{a_{6}}
$$

In Eq. (1) $\mathrm{L}$ is the dimension of the building in the analyzed direction $\left(\mathrm{L}=\mathrm{L}_{\mathrm{x}}\right.$ or $\mathrm{L}_{\mathrm{y}}$ depending if longitudinal or transversal direction is considered), while other parameters are explained above.

Concerning the parameters defining the hysteretic behavior, a simplified approach was adopted in Gaetani d'Aragona et al. [11], assuming that the pinched behavior is symmetric in both the positive and the negative direction and neglecting the strength deterioration mode. This way the number of parameters defining the hysteretic behavior of the spring is limited to 3 pinching parameters and 4 degradation parameters depending on energy. Eq. (2) expresses the stiffness deterioration index $\left(\delta_{\mathrm{ki}}\right)$ as a function of $\mathrm{n}_{\mathrm{cyc}}$ depending on two parameters $\mathrm{g}_{\mathrm{K} 2}$ and $\mathrm{g}_{\mathrm{K} 4}$ :

$$
\delta k_{i}=g K_{2}\left(n_{c y c}\right)^{g K_{4}} \leq g K_{\lim }
$$

Similar expression can be adopted for deterioration of reloading stiffness. For further details, please refer to Gaetani d'Aragona et al. [11].

\section{APPLICATION TO L'AQUILA TOWN}

\subsection{Building inventory}

In the aftermath of L'Aquila earthquake, the Italian government fully funded the reconstruction process of damaged buildings. In Del Vecchio et al. [14] the repair costs for a database composed of 120 residential buildings damaged and repaired after L'Aquila earthquake is analyzed. The repair costs were defined and calculated, after suitable design, by practitioners during the reconstruction process. In this paper, the repair costs by Del Vecchio et al. [14] are adopted as a reference for comparison of repair cost predictions.

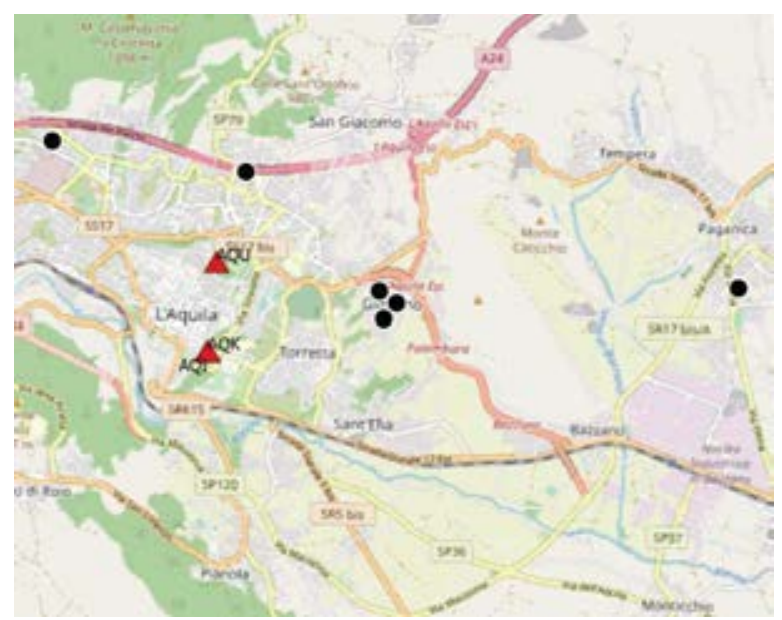

Figure 3: Location of selected buildings (black dot) and accelerometric stations (AQU, AQK). 
Generally, damage and loss assessment of large building portfolios is carried by grouping buildings with similar characteristics (e.g., [15]). However, the method analyzed in this paper lend itself to be applied considering more specific building features as explained above.

For this application, a subset of 6 buildings from the database analyzed in Del Vecchio [14] was selected (see Figure 3). The buildings were selected to be close to the accelerometric station and to have approximately a rectangular shape in plan, to be representative typical heigth distributions in the town $(3,4$, and 5 stories). In Table 1 , the main geometrical features for the analyzed buildings are reported, including the angle of orientation with respect to North, the number of stories $\left(\mathrm{n}_{\mathrm{s}}\right)$, the Surface Area (SA), and the longitudinal and transverse building dimensions $\left(\mathrm{L}_{\mathrm{x}}, \mathrm{L}_{\mathrm{y}}\right)$.

\begin{tabular}{cccccc}
\hline id & Angle to $\mathrm{N}\left({ }^{\circ}\right)$ & $\mathrm{n}_{\mathrm{s}}$ & $\mathrm{SA}\left(\mathrm{m}^{2}\right)$ & $\mathrm{L}_{\mathrm{x}}(\mathrm{m})$ & $\mathrm{L}_{\mathrm{y}}(\mathrm{m})$ \\
\hline 1 & 5 & 5 & 274 & 23.60 & 11.60 \\
2 & 30 & 5 & 256 & 18.00 & 14.20 \\
3 & 45 & 4 & 90 & 12.70 & 7.10 \\
4 & 45 & 4 & 170 & 17.00 & 10.00 \\
5 & 30 & 3 & 210 & 20.40 & 10.30 \\
6 & 35 & 3 & 193 & 16.60 & 11.65 \\
\hline
\end{tabular}

Table 1: Geometry of the selected buildings.

\subsection{Seismic hazard}

The 2009 L'Aquila earthquake was characterized by a magnitude $\mathrm{M}_{\mathrm{w}}=6.3$ and a faultnormal mechanism at about $9 \mathrm{~km}$ depth and an epicentral distance from L'Aquila city of about $6 \mathrm{~km}$. For the analysis, the acceleration time-histories recorded for the L'Aquila earthquake by two different accelerometric stations (AQU, AQK) located in proximity with the analyzed buildings were analyzed. Both ground motion records were recorded on soil class B, with a PGA ranging between $0.25-0.35 \mathrm{~g}$, and were extracted from the Italian Accelerometric Archive (ITACA 3.1, http://itaca.mi.ingv.it/). Figure 4 represents the 5\%-damped Pseudoacceleration spectrum for both records in the N-S and E-W directions.

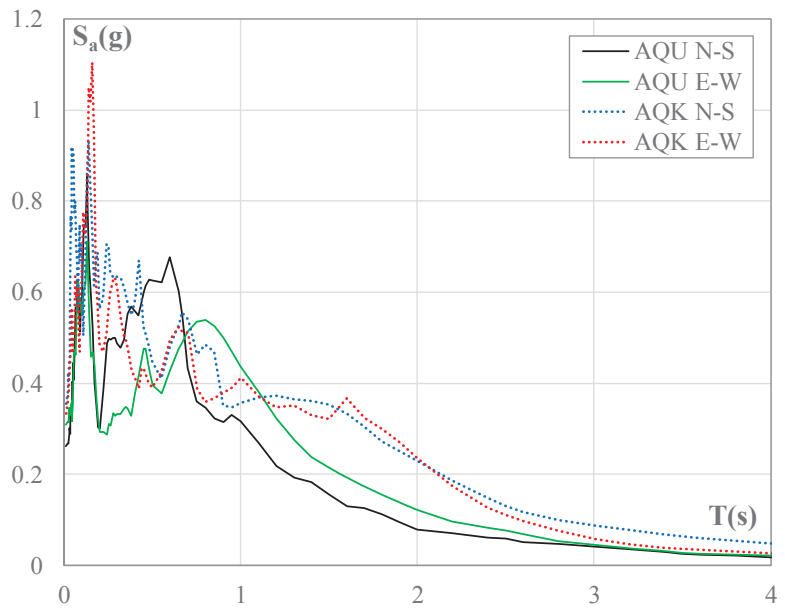

Figure 4: 5\%-damped Pseudo-acceleration spectrum for AQU and AQK ground motion records. 
The horizontal components of the selected records were suitably scaled in order to account for the local amplification at the building site, and rotated according to the orientation of the principal directions of the structure [16].

\subsection{Model and Structural Analysis}

The structural analysis is performed via NTHA for each selected building, considering the simplified Stick-IT model generated according to the procedure described in $\$ 2$ and by adopting median parameters for regression parameters. The building geometry (i.e., approximate longitudinal and transversal dimensions as well as number of stories) necessary to retrieve model features can be obtained with rapid image-based processing techniques (e.g., [17]-[18]). However, in this study, such features were derived from the original building database [14]. The analyzed buildings are assumed approximately regular both in plan and in elevation. Finally, the storey mass is obtained multiplying the surface area $\mathrm{SA}\left(=\mathrm{L}_{\mathrm{x}} \cdot \mathrm{L}_{\mathrm{y}}\right)$ by unit load of 1.1 tons $/ \mathrm{m}^{2}$. For the upper story the unit load is assumed equal to 0.9 tons $/ \mathrm{m}^{2}$.

The infill panel consistency, represented by the infill thickness, shear modulus, and opening percentage are considered as a variable parameter to quantify its influence on the building response and assessment of repair costs. To this end, three different thicknesses for the infill panels are considered, $20 \mathrm{~cm}-24 \mathrm{~cm}-30 \mathrm{~cm}$, corresponding to weak, medium and strong infill, respectively, according to Hak et al. [19]. To simulate different infill thicknesses, the procedure proposed in [12] is adopted. The opening percentage is considered constant and equal to $20 \%$ of the area of the infill panel. The adoption of different opening percentages along the height also significantly influences the builing response and the distribution of lateral deformations (e.g., [21]-[22]). However, this effect is not investigated in this study.

For each one of the two ground motion records in $\$ 3.2$, each model was analyzed by rotating and scaling the ground motion components in the two separate directions (longitudinal and transverse).

The Stick-IT model is able to predict the intensity and distribution of Engineering Demand Parameters such as Interstory Drift Ratios (IDRs) and Peak Floor Accelerations (PFAs). However, in this study only IDRs are evaluated, since only damage experienced by driftsensitive components is considered.

As an example, Figure 5 depicts the maximum IDR profiles obtained for the Stick-IT model of the building with 'id 1' (see Table 1) subjected to the two records AQU and AQK and analyzed in the two orthogonal directions. As an assumption, the longitudinal direction is the direction of maximum extension of the building in plan. For this reason, due to the largest amount of infill panels, it represents the direction characterized by higher capacity to withstand to lateral loads, and with lower deformability. In particular, due to the lower excursion in the nonlinear range for the longitudinal direction, the IDRs for AQU and AQK are much closer than those obtained in the transverse direction, where the two records may lead to significantly different IDR (due to concentration of damage) and the maximum IDR may be localized in a different story.

In particular, the Figure 5(a)-(c) depicts the shape of IDR for varying infill thicknesses. Obviously, the higher the infill panel thickness, the lower the maximum experienced IDR. However, while for the transverse direction this effect is evident, in the longitudinal direction this effect is negligible. Further, by keeping as a reference the panels with $t_{\mathrm{w}}=24 \mathrm{~cm}$, the maximum scatter between different thicknesses is obtained for the AQK record in the transverse direction, at the third story, where a scatter of $76 \%$ in IDR value is achieved. The effect of infill thickness produces a significant variation of IDR [22], and thus of the potential damage experienced by drift-sensitive components. 

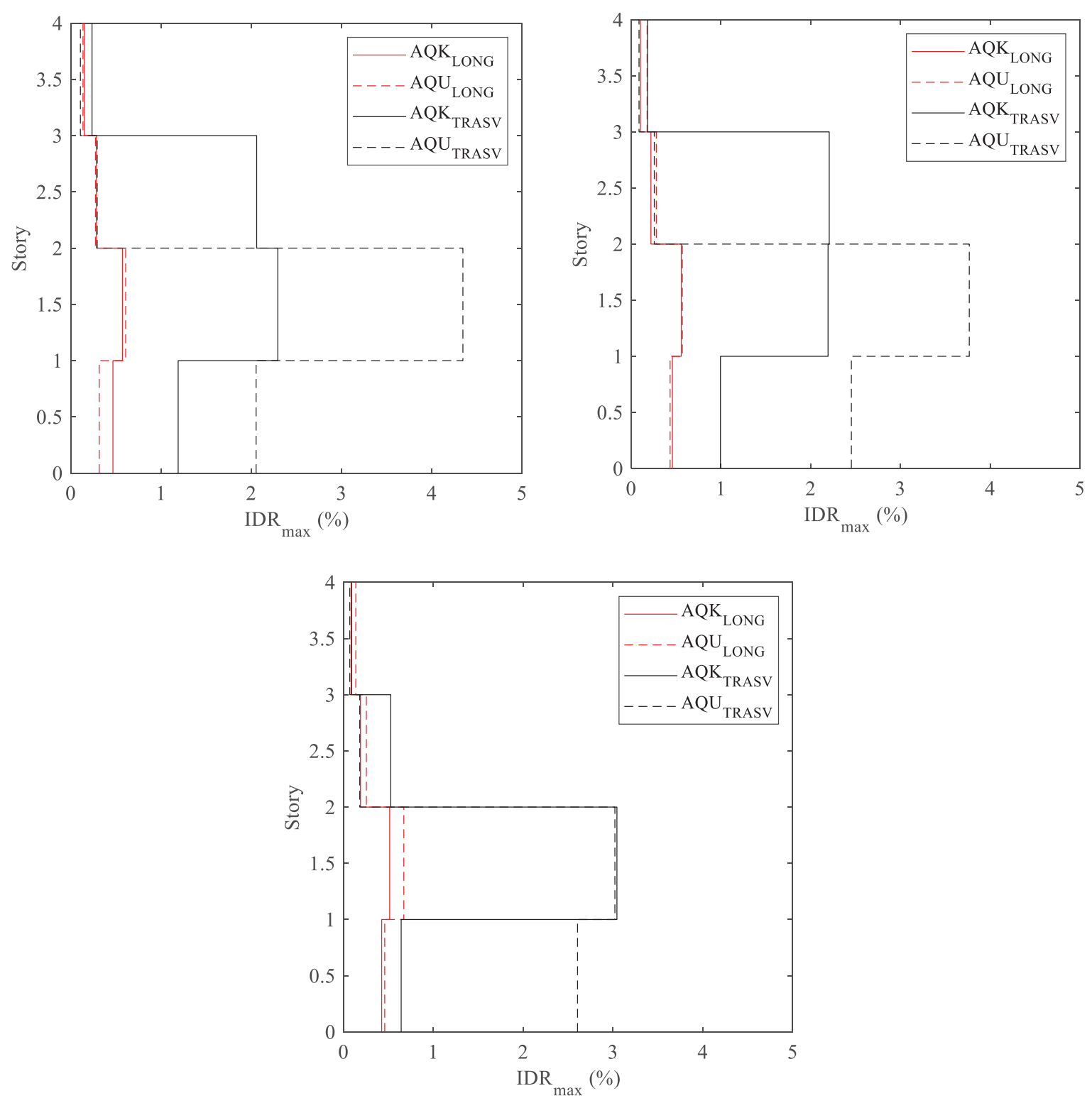

Figure 5: Distribution of maximum IDRs for (a) $t_{w}=20 \mathrm{~cm}$, (b) $t_{w}=24 \mathrm{~cm}$ and (c) $t_{w}=30 \mathrm{~cm}$ for building 'id 1'.

\subsection{Damage and Loss assessment}

In this section the damage and loss assessment is performed adopting global indicators (i.e., EDPs) as a proxy for damage prediction. To this end, suitable EDP-dependent damage functions for both structural and nonstructural components specifically calibrated for typical Italian standard components need to be adopted. For residential buildings the largest amount of repair costs mainly depends on damage to infills and partitions [14]. For this reason, this paper limits the assessment of repair costs only referring to the costs related to repair of infill, partitions and integrated components (i.e., plumbing and electrical system, doors and windows).

With reference to the infill walls and interior partitions, Del Gaudio et al. [23] recently proposed damage fragility functions for typical Italian hollow clay infills, with and without 
openings, based on the analysis of a large experimental dataset. The proposed values were adopted to capture the observed damage experienced by exterior and interior infills at different stories.

Direct losses associated to infills, partitions and integrated components are calculated by adopting the cost function developed in Del Vecchio et al. [14] for Italian standards. The functions include the cost of all the repair actions needed to restore the building to its preevent conditions depending on the presence/absence of openings, the damage state experienced, and the extension of the damaged components.

The extent of damageable components need to be quantified based on a simulated architectural layout that can be obtained based on the procedure reported in [12]. In particular, the procedure assumes that infill wall panels extend along the whole exterior perimeter of the building, while partitions are located along each bay in each building direction. Further, it is considered that the $50 \%$ of exterior infill panels has openings while the $50 \%$ has no openings, and interior partitions are always classified as elements with openings. The simulation of the architectural layout, significantly influences the prediction of repair costs, while it has no influence on the building structural response. Thus, in this section the extent of partitions will be also varied in order to quantify the influence of this assumption. In particular, it will be considered the $100 \%$ of the extension of the simulated layout and then, the $50 \%$ and the $150 \%$ of the extension obtained for interior partitions. For instance $50 \%$ means that only the one half the bays in the longitudinal and transverse direction of the building, the number and extension of which depends on the simulated design, are filled with partitions. Finally $150 \%$ of the extension of the simulated layout means that there is the $50 \%$ more of partitions with respect to those simulated. Instead, the extension of perimeter infills is considered invariant.

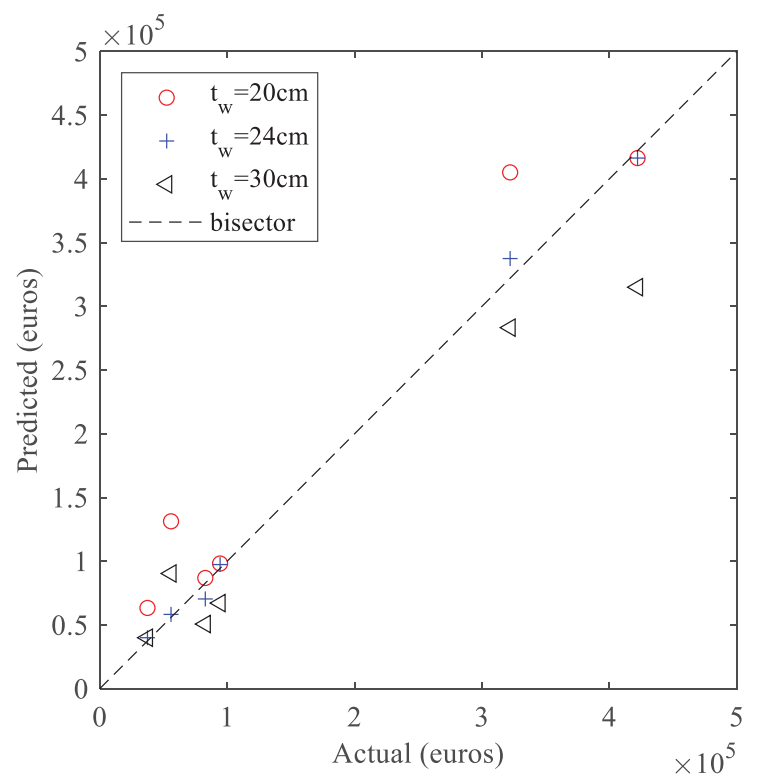

Figure 6: Actual vs Predicted repair costs to infill panels, partitions and integrated components for $t_{\mathrm{w}}=20 \mathrm{~cm}$ $24 \mathrm{~cm}-30 \mathrm{~cm}$.

The damage level was calculated by adopting as input parameters the IDR for each story and direction obtained in $\S 3.3$. The maximum repair cost between those obtained considering the records AQU and AQK is assumed as a reference. By summing up the repair cost between each story and direction, the total repair cost for infills, partitions and integrated components is calculated. For each story, it is assumed that the level of damage for the generic type of 
component (i.e., infill/partition with openings or without openings) is the same throughout the story, but may be different between orthogonal directions. Figure 6 depicts the comparison between the actual and the predicted repair cost obtained by adopting different infill wall thicknesses (and 100\% of the extension of infill/partitions obtained via simulated architectural layout). It can be noted that the prediction is in general acceptable, and it is most approximated when adopting $t_{\mathrm{w}}=24 \mathrm{~cm}$.

In particular, for $t_{\mathrm{w}}=20 \mathrm{~cm}$ the mean (median) ratio between the predicted and the actual repair cost for infills, partitions and integrated components is $1.39(1.15)$. For $t_{w}=24 \mathrm{~cm}$ these ratios reduces to $1.00(1.04)$, and for $t_{\mathrm{w}}=30 \mathrm{~cm}$ to $0.93(0.81)$. The maximum scatter between predicted and actual repair cost is achieved for $t_{\mathrm{w}}=20 \mathrm{~cm}$ and is of $134 \%$. Thus, the mean consistency for infill panel seems to lead to more reliable predictions for repair costs. However, this assumption should be validated on a larger building database.

Another assumption regards the extension of damageable components. This is expected to be an influential parameter in terms of estimation of repair cost, characterized by a larger dispersion due to extreme variability of the possible configurations of the interior architectural layout. Obviously, the incidence on the total repair cost due to the different architectural layout of interior partitions mainly depends on the surface area of the building.

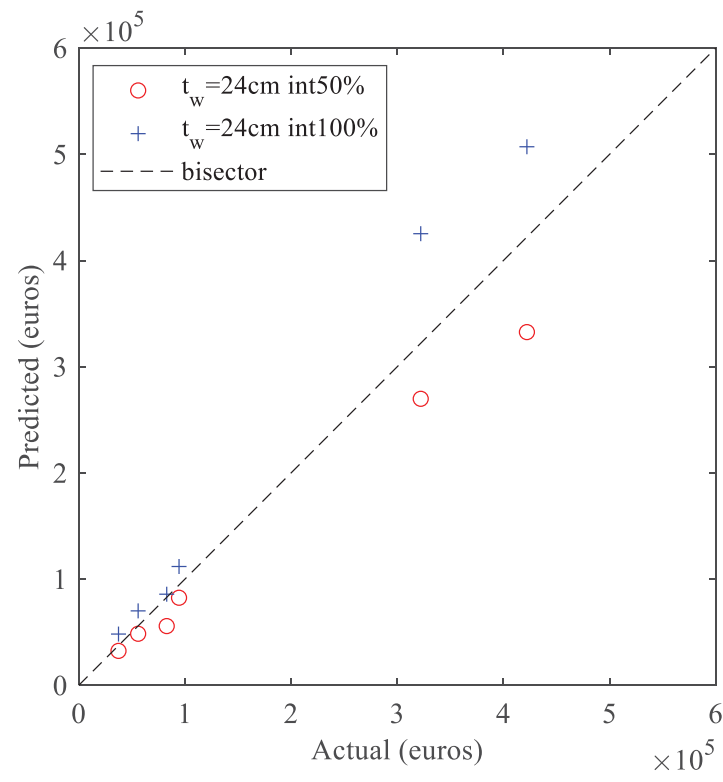

Figure 7: Actual vs Predicted repair costs to infill panels, partitions and integrated components for $t_{\mathrm{w}}=24 \mathrm{~cm}$ and considering $50 \%$ and $150 \%$ of simulated architectural layout for interior partitions.

As evidenced in Figure 7, which depicts the comparison between the actual and predicted repair cost considering different extensions for interior partitions (architectural layout), accounting for lower extension leads to underprediction or repair costs, while larger extension to overprediction of repair costs. In this case, by adopting the IDRs obtained considering the mean infill consistency for the model, the adoption of $50 \%$ of initial simulation of partition layout leads to a median (and median) underestimation of repair costs with respect to the actual ones of $15 \%$ and to an overestimation of $23 \%$ if a $150 \%$ of the initial layout is adopted, suggesting that the original simulated layout leads to the best prediction of repair costs. Finally, the maximum scatter between predicted and actual repair cost of $\pm 30 \%$ is obtained for the single building. 


\section{CONCLUSIONS}

This study presents the first comparisons of a simplified loss assessment procedure to evaluate expected seismic losses at the large scale.

The procedure is based on the adoption of a simplified multi degree of freedom MDOF Stick-IT model introduced in [11], which allows to rapidly calculate the performance of infilled RC buildings in terms of engineering demand parameters EDP such as interstory drift ratios, IDRs, and peak floor accelerations, PFAs, using Nonlinear Response History Analyses.

The loss assessment procedure was tested on a set of 6 buildings damaged and repaired after the 2009 L'Aquila earthquake. Firstly, main building features such as in plan dimensions and story number were retrieved, and a building inventory defined. Then, the StickIT model were defined for each one of the considered building. Next, after rotating and scaling two ground motion records for the L'Aquila earthquake, NRHA were performed by adopting the Stick-IT models. The response for each typology was expressed in terms of maximum IDR along building height. Finally, by adopting suitable cost functions, the repair costs for infills, partitions and integrated components are calculated and compared to the actual repair costs for these components.

In this study the validity of some assumptions to be adopted for large scale assessment purposes were tested. Firstly, the model requires the definition of the consistency of infill panels that contribute to the resistance and deformability against lateral loads. While this parameter is easy to define at the building level, it is of difficult definition for a large building portfolio for which only low-level information are available. By considering three possible consistencies according to the technical literature (weak, medium and strong), it has been found that the 'mean' consistency for infill panels generally leads to the best prediction for repair costs of infill, partitions and integrated components, while the other generally leads to an overestimation or underestimation of repair costs due to a different prediction of lateral deformations that is about $40 \%$ in terms of mean error for the considered building set, while a maximum scatter of $135 \%$ may be achieved for the single building.

Further, also the simulated design procedure adopted to quantify of the extension of damageable components was tested. This is characterized by a large dispersion due to extreme variability of the possible configurations of the interior architectural layout. The influence of this quantification alter the prediction of repair cost of about $20 \%$ in mean terms for the considered building set, while it leaded to a maximum scatter of about $30 \%$ for the single building. However, it is expected that the influence of this parameter is conditioned on the in plane shape ratio and the surface area of the building, and further studies are required to quantify the effect of these hypoteses.

In this proposed study, median values for definition of Stick-IT model parameters as proposed in [11] were employed. However, due to the large amount of uncertainties in the StickIT model definition, a fully probabilistic framework application would allow a more realistic assessment of repair costs. Moreover, time-based assessment of expected seismic losses could be performed by repeating the evaluation at various level of earthquake intensity according to the seismic hazard of the area. Future studies will address these issues.

Despite this application is limited to the assessment of infills, it shows the possibility to easily implement the proposed methodology for rapid estimation of expected losses at the large scale. Other cost-functions could be adopted, suitably accounting, e.g. for costs of acceleration sensitive components. 


\section{REFERENCES}

[1] Porter KA. An overview of PEER's performance-based earthquake engineering methodology. Proceedings of 9th International Conference on Applications of Statistics and Probability in Civil Engineering, 2003.

[2] Gaetani d'Aragona M, Polese M, Prota A. Effect of Masonry Infill Constitutive Law on the Global Response of Infilled RC Buildings, Buildings; 11(2), 57; https://doi.org/10.3390/buildings11020057.

[3] Gaetani d'Aragona M, Polese M, Di Ludovico M, Prota A. Simplified assessment of expected seismic losses for as built and retrofitted RC buildings, proceedings of COMPDYN 2017 6th ECCOMAS Thematic Conference on Computational Methods in Structural Dynamics and Earthquake Engineering, Rhodes Island, Greece, 15-17 June 2017.

[4] Gaetani d'Aragona M, Polese M, Cosenza E, Prota A. Simplified Assessment of Maximum Interstory Drift for RC buildings with Irregular Infills Distribution Along the Height, Bull Earthquake Engineering, 2019; 17(2), 707-736. https://dx.doi.org/10.1007/s10518-018-0473-y.

[5] Gaetani d'Aragona M, Polese M, Di Ludovico M, Prota A. Seismic vulnerability for RC infilled frames: Simplified evaluation for as-built and retrofitted building typologies. Buildings, 2018; 8(10): 137. https://doi.org/10.3390/buildings8100137.

[6] Polese M, Gaetani d'Aragona M, Di Ludovico M, Prota A. Sustainable selective mitigation interventions towards effective earthquake risk reduction at the community scale. Sustainability, 2018; 10, 2894. https://doi.org/10.3390/su10082894.

[7] Gaetani d'Aragona, M, Polese, M, Prota, A. Simplified model calibration for dynamic response assessment of infilled RC buildings. In Proceedings of the 7th ECCOMAS Thematic Conference on Computational Methods in Structural Dynamics and Earthquake Engineering, Crete, Greece, 24-26 June 2019.

[8] Xiong C, Lu XZ, Lin XC, Xu Z, Ye LP. Parameter determination and damage assessment for THA-based regional seismic damage prediction of multi-story buildings. J. Earthq. Eng. 2017; 21(3): 461-485.

[9] Lu XZ, Lu B, Xu Z, Xiong C, \& Zeng X. High performance computing for regional building seismic damage simulation. Procedia Engineering. 2017; 198: 836-844.

[10] Dao ND, Ryan KL, \& Nguyen - Van H. Evaluating simplified models in predicting global seismic responses of a shake table - test building isolated by triple friction pendulum bearings. Earthquake Engineering \& Structural Dynamics. 2019; 48(6):594-610.

[11] Gaetani d'Aragona, M, Polese, M, Prota, A. Stick-It: A simplified model for rapid estimation of IDR and PFA for existing low-rise symmetric infilled RC building typologies. $\begin{array}{llll}\text { Engineering } & \text { Structures, } & 2020 ; 11182 .\end{array}$ https://doi.org/10.1016/j.engstruct.2020.111182.

[12] Gaetani d'Aragona, M, Polese, M, Di Ludovico, M, Prota, A. The use of Stick-It model for the prediction of direct economic losses. Earthquake Engineering and Structrural Dynamics, 2021. https://doi.org/10.1002/eqe.3429. 
[13] OpenSees. Open system for earthquake engineering simulation OpenSees frameworkVersion 3.2.2. Pacific Earthquake Engineering Research Center, Univ. of California, Berkeley, 2021.

[14] Del Vecchio C, Di Ludovico M, \& Prota A. Repair costs of reinforced concrete building components: from actual data analysis to calibrated consequence func-tions. Earthquake Spectra, 2020; 36(1):353-377-

[15] Polese M, Di Ludovico M, Gaetani d'Aragona M, Prota A, Manfredi G. Regional vulner-ability and risk assessment accounting for local building typologies, International Journal of Disaster Risk Reduction, 2020; 43:101400. https://doi.org/10.1016/j.ijdrr.2019.101400

[16] Somerville P. Characterizing near fault ground motion for the design and evaluation of bridges, in Proceedings of the Third National Seismic Conference and Workshop on Bridges and Highways 01/2002, 28 April-1 May 2002, Portland, OR.

[17] Gaetani d'Aragona M, Polese M, Tocchi G, Prota A. Application of a simplified nonlinear model to predict seismic losses for infilled RC buildings at the territorial scale. In Proceedings of the 17th Conference on Earhquake Engineering, Sendai, Japan, September $13^{\text {th }}$ to $18^{\text {th }} 2020$.

[18] Polese M, Gaetani d'Aragona M. Seismic event scenarios, pp 67-110, in Study of the seismic risk scenarios in support of Civil Protection Plans for the town of Pozzuoli, DoppiaVoce ed. (in Italian).

[19] Hak S, Morandi P, Magenes G, \& Sullivan TJ. Damage control for clay masonry infills in the design of RC frame structures. Journal of Earthquake Engineering, 2012; 16(1): $1-35$.

[20] Gaetani d'Aragona M, Polese M, Cosenza E, Prota A. Simplified Assessment of Maximum Interstory Drift for RC Buildings with Irregular Infills Distribution Along the Height, Bull Earthquake Engineering, 2019; 17(2), 707-736. https://dx.doi.org/10.1007/s10518-018-0473-y.

[21] Gaetani d'Aragona M, Polese M, Prota A. Influence factors for the assessment of maximum lateral seismic deformations in Italian multistorey RC buildings, proceed-ings of COMPDYN 2017 6th ECCOMAS Thematic Conference on Computational Methods in Structural Dynamics and Earthquake Engineering, Rhodes Island, Greece, 15-17 June 2017.

[22] Gaetani d'Aragona M, Polese M, Prota A. Effect of Masonry Infill Constitutive Law on the Global Response of Infilled RC Buildings. Buildings, 2021; 11(2), 57; https://doi.org/10.3390/buildings11020057

[23] Del Gaudio C, De Risi MT, Ricci P, \& Verderame GM. Empirical drift-fragility functions and loss estimation for infills in reinforced concrete frames under seismic loading. Bulletin of Earthquake Engineering, 2019; 17(3):1285-1330. 